\title{
Successful near-term pregnancy outcome after repair of a dissecting thoracic aortic aneurysm at 14 weeks gestation
}

\author{
[Dénouement heureux d'une grossesse menée presque à terme à la suite de la réparation \\ d'un anévrysme disséquant de l'aorte thoracique à 14 semaines de gestation]
}

Monala Tilak MD, Jacqueline Smith MD, Dan Rogers MD, Pamela Fox MD, Muhammad Muntazar MD, Marvin Peyton MD

Purpose: We report the anesthetic management for a scheduled Cesarean section of a 29-yr-old female who previously had a repair of her dissecting thoracic aortic aneurysm during the $14^{\text {th }}$ week of her pregnancy.

Clinical features: A 29-yr-old female with a history of hypertension and previously diagnosed aortic dissection secondary to suspected Marfan's syndrome, presented to our institution for the first time after she became pregnant. A transesophageal echocardiogram revealed a dissecting aortic aneurysm greater than $8 \mathrm{~cm}$ in diameter beginning distal to the left subclavian artery and extending into the descending thoracic aorta. The patient was counseled in great detail about the risk of rupture with continuing pregnancy. She refused termination and chose elective repair of the aneurysm, with continuation of the pregnancy. Partial repair of the thoracic aneurysm was undertaken when the pregnancy was $13^{5 / 7}$ weeks by ultrasound dates. She was subsequently maintained on labetolol and hydralazine for blood pressure control. A decision was made to proceed with a Cesarean section at 32 weeks. After placement of a radial artery catheter and two large peripheral iv catheters, she received a combined spinal-epidural anesthetic. A male infant with Apgars of 7 and 7 at one and five minutes was delivered.

Conclusions: Aortic dissection in pregnancy may have catastrophic results. Undoubtedly, it presents unique challenges for anesthetic and obstetrical management. With appropriate care and surgical correction of the dissecting aneurysm early in pregnancy, a successful outcome for the pregnancy was possible.
Objectif: Présenter l'anesthésie réalisée pour une césarienne réglée chez une femme de 29 ans, opérée pour la réparation d'une dissection aortique pendant la $14^{\mathrm{e}}$ semaine de grossesse.

Éléments cliniques: Une femme de 29 ans, connue pour hypertension et chez qui une dissection aortique secondaire à un syndrome de Marfan présumé avait été diagnostiquée, a consulté pour la première fois après le début de sa grossesse. Une échocardiographie transœsophagienne a révélé un anévrysme disséquant de l'aorte plus grand que $8 \mathrm{~cm}$ de diamètre, s'étendant de la partie distale de l'artère sous-clavière gauche touchant l'aorte thoracique descendante. La patiente a reçu des informations détaillées sur le risque de rupture aortique avec la poursuite de la grossesse. Elle a choisi de poursuivre la grossesse et de subir la réparation réglée de l'anévrysme. La réparation partielle de l'anévrysme thoracique $a$ été entreprise à $13^{5 / 7}$ de grossesse, d'après les dates fournies par l'échographie. La tension artérielle a ensuite été contrôlée avec du labétolol et de l'hydralazine. La césarienne a été faite à 32 semaines. Elle comportait la mise en place d'un cathéter de l'artère radiale et de deux grands cathéters périphériques iv ainsi qu'une anesthésie rachidienne et péridurale combinée. Un enfant mâle est né, avec un indice d'Apgar de 7 et 7 à une et cinq minutes après la naissance.

Conclusion : Une dissection aortique pendant la grossesse peut avoir des conséquences catastrophiques. Elle représente, à n'en pas douter, des défis à part pour la prise en charge anesthésique et obstétricale. Dans le cas présent, des soins appropriés et la correction chirurgicale de l'anévrysme, tôt pendant la grossesse, ont assuré un dénouement heureux.

From the Department of Anesthesiology, University of Oklahoma Health Sciences Centre, Oklahoma City, Oklahoma, USA.

Address correspondence to: Dr. Monala Tilak, Department of Anesthesiology, University of Oklahoma Health Sciences Centre, 920

Stanton L. Young Blvd., Room WP 2530, Oklahoma City, OK 73104, USA. Phone: 405-271-4351; Fax: 405-271-8695;

E-mail: Monala-tilak@ouhsc.edu

There are no funding sources (departmental, hospital, institutional, commercial, etc.) supporting the submitted work, any commercial or non-commercial affiliations that are or may be received to be a conflict of interest with the work, and any other associations such as consultancies.

Accepted for publication November 18, 2004.

Revision accepted May 2, 2005.

Final revision accepted July 6, 2005. 
A ORTIC dissection is often cited as a complication of Marfan's syndrome, being reported in as many as one third of the patients at autopsy. ${ }^{1}$ In these patients, aortic dissection occurs at an early age and is usually unaccompanied by hypertension. Aortic dissection in pregnancy can be catastrophic. It has been estimated that $50 \%$ of all aortic dissections in women less than $40 \mathrm{yr}$ of age occurs during pregnancy, more commonly in the later months, leading to the speculation that the hemodynamic alterations during pregnancy may play a role. ${ }^{2}$ While systemic hypertension is the most common etiological risk factor for aortic dissection, Marfan's syndrome, other congenital cardiovascular abnormalities and pregnancy-induced changes in the vessel wall are also associated with this entity. ${ }^{3}$ Several authors have suggested that physiologic, cardiovascular and hormonal changes in pregnancy may result in an increase of the shearing stress on the aortic wall accompanied by weakening of some of its elements, thus predisposing the pregnant patient to aortic dissection. ${ }^{4} \mathrm{We}$ report a case of a 29-yr-old woman with a known aortic dissecting aneurysm for two years who presented to us initially, for the management of her pregnancy. She had partial repair of her dissecting aneurysm during the $14^{\text {th }}$ week of her pregnancy, and successfully proceeded to 32 weeks when she delivered a live infant by Cesarean section.

\section{Clinical features}

All personal identifying details have been excluded and consent for publication of this manuscript obtained in accordance with our institutional guidelines. A 29-yrold, primigravid female, $180 \mathrm{~cm}$ tall and weighing 135 $\mathrm{kg}$, with a history of chronic hypertension and suspected Marfan's syndrome, underwent partial repair of a type III thoracic aortic dissecting aneurysm during her $14^{\text {th }}$ week of pregnancy. The dissecting aneurysm was identified two years previously when the patient presented at another institution for complaints of "burning" back pain and left upper quadrant pain, which led to serial imaging studies. She had previously lost a fetus at eight weeks. Her father, two uncles and a brother had died from acute cardiac events. The patient was counseled in great detail about the risk of continuing the pregnancy, but she chose elective repair of the aneurysm with continuation of the pregnancy. Partial repair of the thoracic aneurysm was undertaken when the pregnancy was $13^{5 / 7}$ weeks by ultrasound dates. The surgical procedure involved replacement of the proximal area of the dissection with a synthetic graft during atrial-femoral bypass without circulatory arrest. The surgeon elected not to proceed with repair of the

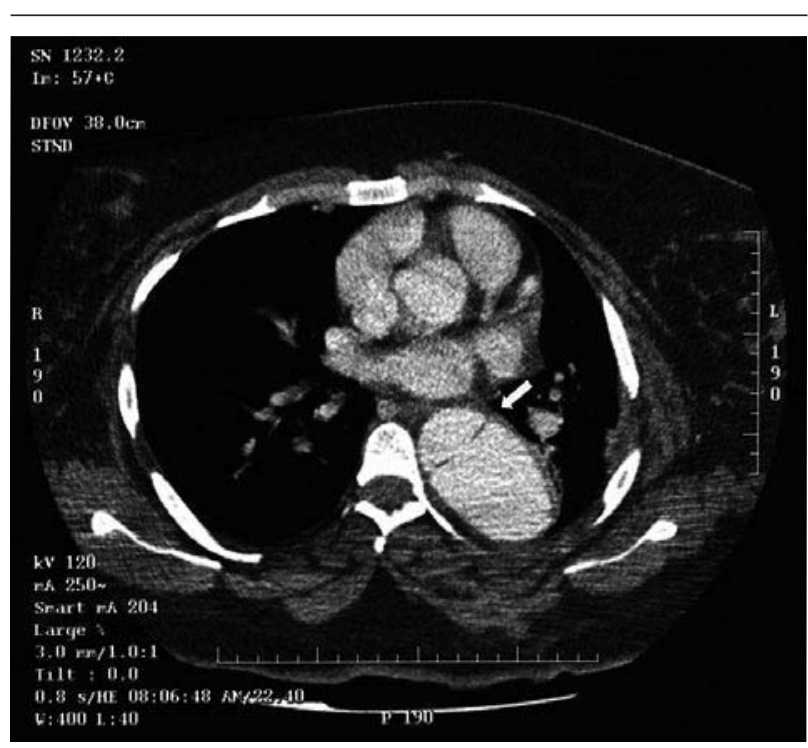

FIGURE Contrast computed tomography scan showing the residual type III dissecting aneurysm of the aorta (arrow) with a maximal diameter of $8 \mathrm{~cm}$. The arrow points to the intimal flap with a smaller true lumen above it, and a larger false lumen below.

distal aorta to protect the pregnancy and minimize the risk of spinal cord damage. Repair of the distal aorta would have needed an extension of the thoracotomy to a laparotomy, prolonged the length of the operation, required larger doses of anticoagulation and increased the risk for hypothermia, which would have been dangerous to the fetus. ${ }^{4}$ Only when the entire descending thoracic aorta is grossly aneurysmal should one consider replacing the entire descending aorta. ${ }^{5}$ If resection of the distal thoracic aorta can be avoided, the perfusion to the spine is less likely to be affected, minimizing the risk of spinal cord ischemic injury. ${ }^{6}$ During the procedure, the patient received two units of packed red blood cells, $1 \mathrm{~L}$ of fresh frozen plasma, one apheresis unit $(700 \mathrm{~mL})$ of platelets, 20 units of cryoprecipitate and four units of cell saver blood. The postoperative course was noteworthy for lower visual field loss in her right eye consistent with posterior ischemic optic neuropathy and left otitis externa, both of which resolved without sequelae.

Following the surgery, the patient was followed-up in the high-risk obstetric clinic and experienced no further problems. Her blood pressure was adequately controlled with labetalol and hydralazine. Three weeks after surgery, at $16^{4 / 7}$ weeks of gestation, the patient returned with complaints of "tearing" chest pain. A computerized tomography (CT) scan with contrast was done to rule out an extension of the 
TABLE Hemodynamic variables during anesthesia for Cesarean section

\begin{tabular}{lllll}
\hline Time in min & Systolic blood pressure $(\mathrm{mmHg})$ & Diastolic blood pressure $(\mathrm{mmHg})$ & Heart rate (beats.min $\left.{ }^{-1}\right)$ & Oxygen saturation (\%) \\
\hline 00 & 130 & 62 & 78 & 100 \\
15 & 148 & 82 & 95 & 100 \\
30 & $155^{*}$ & 95 & 95 & 100 \\
45 & 116 & 55 & 78 & 100 \\
60 & $100^{* *}$ & 55 & 70 & 100 \\
75 & 115 & 58 & 76 & 100 \\
90 & 124 & 68 & 87 & 100 \\
105 & 122 & 62 & 66 & 100 \\
120 & 124 & 64 & 70 & 100 \\
\hline${ }^{*}$ Spin
\end{tabular}

*Spinal anesthesia established; ** $5 \mathrm{mg}$ ephedrine $i v$. Delivery was at $67 \mathrm{~min}$.

dissection. This showed a type III dissecting aortic aneurysm with a maximal diameter of $8 \mathrm{~cm}$ (Figure) extending into the abdominal and pelvic aorta with a stable configuration of the true and false lumen, as well as chronic hematoma over the graft with no active extravasation. The maximal diameter obtained on transesophageal echocardiography during the $12^{\text {th }}$ week of gestation was $6.7 \mathrm{~cm}$. The patient remained asymptomatic after that episode.

A decision was made to proceed with a Cesarean section at $32^{2 / 7}$ weeks due to the slight interval enlargement of the aneurysm and the worry that further continuation of the pregnancy with its associated cardiovascular changes might increase the risk of rupture. $^{7}$ She received two doses of steroids over $48 \mathrm{hr}$. The procedure took place in the cardiothoracic operating room with the cardiothoracic team on standby. All risks, including those to the mother and baby, benefits and alternatives were explained to the patient. Preoperative blood pressure was $130 / 80 \mathrm{mmHg}$ with a heart rate of 80 beats. $\mathrm{min}^{-1}$. Preoperative laboratory results were as follows: hemoglobin 11.4 $\mathrm{g} \cdot \mathrm{dL}^{-1}$, hematocrit $34.9 \%$ and platelets $312 \mathrm{k} \cdot \mathrm{mm}^{3}$. The patient was given a $10 \mathrm{~mL} \cdot \mathrm{kg}^{-1}$ bolus of lactated Ringer's as well as sodium citrate, metoclopramide and famotidine, for prophylaxis against aspiration pneumonia. She was then taken to the operating room where standard monitors were applied. A 20-gauge intra-arterial catheter was placed in her left radial artery and a large bore iv access was obtained in each arm. The patient was then placed in the sitting position. Under aseptic conditions, an 18-gauge Tuohy needle was inserted in the L3-L4 interspace and the epidural space was identified (with some difficulty), using a loss of resistance technique with saline. We were unable to perform a spinal injection by the co-axial technique so an epidural catheter was threaded. The epidural catheter was tested with $3 \mathrm{~mL}$ of $1 \%$ lidocaine with 1:200,000 epinephrine with no adverse effects. We then performed a spinal anesthetic in the L2-L3 interspace with a 24 gauge Whitacre (BD Medical Systems, Franklin Lakes, NJ, USA) spinal needle and $2.0 \mathrm{~mL}$ of $0.75 \%$ bupivacaine with $25 \mu \mathrm{g}$ of fentanyl. The patient was then placed supine with left uterine displacement. A T-4 level of anesthesia to touch was obtained and an extended prepping and draping of the patient was performed in the event that thoracotomy for vascular repair should be needed. The patient's blood pressure remained stable throughout the procedure (Table) and the obstetrician proceeded with a primary low transverse Cesarean section with forceps assistance. A male infant was delivered with Apgars of 7 and 7 at one and five minutes, respectively. Following delivery of the infant, the patient also underwent elective sterilization with bilateral partial salpingectomy. Estimated blood loss for the procedure was approximately 800 $\mathrm{mL}$ and total intraoperative fluids administered were $1800 \mathrm{~mL}$ of lactated Ringer's. The epidural catheter was injected with $4 \mathrm{mg}$ of morphine for postoperative analgesia. The postoperative courses for both the mother and infant were uneventful.

Approximately five months post-delivery, the patient returned for elective repair of the descending thoracic dissecting aneurysm. Postoperatively, severe bleeding, hypotension and hypovolemic shock necessitated surgical re-exploration and multiple transfusions. The postoperative course was complicated by paraplegia thought to be secondary to anterior spinal artery compromise. Neurological examination revealed normal upper extremities. The lower extremities were flaccid with no movement or deep tendon reflexes. There was a $\mathrm{T}_{4}$ level sensory loss to crude touch and pain with preserved vibration sense. This was consistent with an anterior spinal artery insult. 


\section{Discussion}

A literature search did not reveal any published cases of aortic dissection in pregnancy that was repaired as early as 14 weeks of gestation, which proceeded to a live birth.

Aortic dissection is commonly associated with chronic hypertension, however, other risk factors such as atherosclerosis, endocrine abnormalities, trauma, pregnancy and diseases involving abnormalities of elastic tissues (Marfan's syndrome) can play a role in the development of a dissecting aneurysm. ${ }^{1}$ Prior studies have found that approximately half of aortic dissections reported in females younger than $40 \mathrm{yr}$ of age are associated with pregnancy. ${ }^{2}$ Pregnancy associated changes related to the cardiovascular system, including a sustained increase in cardiac output, pulse pressure, as well as the histological changes that alter the media of the aorta, are very likely related to the increased risk of aortic dissection. These changes can be catastrophic in a female with Marfan's syndrome. ${ }^{7}$ With pregnancy, the histological changes that have been described with reference to the aorta, include fragmentation of the reticulum, attenuation of the elastica with increased corrugation, and a decrease in the amount of acid mucopolysaccharides. These changes are likely to increase the vulnerability of the aorta to dissection. ${ }^{8}$ Symptoms such as a tearing or ripping sensation in the chest, abdominal or back pain should alert clinicians to the diagnosis of aortic dissection. Our patient had presented two years previously to another institution with burning back pain and left upper quadrant pain, and the diagnosis was made with the aid of an aortogram and an angiocardiogram. Definitive diagnosis and sequential monitoring during pregnancy is best performed with transesophageal echocardiography, CT scan or magnetic resonance imaging. The diagnostic accuracy of transesophageal echocardiography is extremely high (up to $99 \%$ ). The use of contrast makes the CT scan less favourable in pregnancy. Angiography, though sensitive, is an invasive procedure, requiring a significant dose of radiation as well as iv contrast material. Therefore it is not the preferred diagnostic procedure in pregnancy. ${ }^{4}$ It also carries a substantial risk of procedural complications and diagnostic pitfalls. ${ }^{9}$

The treatment of aortic dissection in pregnancy is based on its location and severity, and the gestational age. Aortic dissections that occur in the ascending aorta (Debakey types I and II) need surgical repair, while aneurysms of the descending aorta (Debakey type III) allow for consideration of medical management. ${ }^{2}$ In a patient with a fetus of less than 28 weeks gestation, aortic repair without delivery is the sug- gested treatment and in a fetus with a gestational age greater than 32 weeks, Cesarean section coupled with subsequent aortic repair is recommended. Gestational age of 28 to 32 weeks is an unclear area where the condition of the mother and the fetus must be evaluated at length. ${ }^{10}$ The cardiovascular changes during pregnancy can be particularly dangerous in this situation because of the increased pulsatile shear stress on the aortic wall. ${ }^{11}$ Correct medical management consists of reduction of arterial pressure and velocity of ventricular contractions with antihypertensive agents and $B$ blockers. Beta-blockers may have important maternal and fetal side effects and should be used cautiously. They can increase the uterine tone and contractility and decrease umbilical blood flow. ${ }^{12}$ Propranolol may be associated with intra-uterine growth retardation. Hydralazine, labetalol, and nifedipine have been used safely in pregnant patients. Nitroprusside and nitroglycerine have also been used, but carry the risk of fetal cyanide toxicity and loss of fetal heart beat-tobeat variability, respectively. ${ }^{2}$ This patient was treated for hypertension using labetalol and hydralazine following her initial repair, early in pregnancy.

The current literature offers minimal information with regard to the induction of anesthesia for obstetrical delivery in the pregnant patient with an incompletely repaired dissecting aortic aneurysm. The anesthetic considerations of an existing aortic aneurysm applied during the management of the Cesarean section. The goal of anesthetic management is to maintain a stable hemodynamic status avoiding both hypotension, which would jeopardize uteroplacental flow, as well as hypertension which might increase the risk of the aneurysm rupturing. General anesthesia carries the risk of a hypertensive response to laryngoscopy and intubation which could have disastrous consequences, although this can be prevented with the use of appropriate pharmacology. ${ }^{3}$ Regional anesthesia avoids this problem, although there is a risk of an abrupt sympathectomy that can be induced with spinal anesthesia in a patient on concurrent treatment with B-blockers. ${ }^{2}$ The patient's hemodynamic status must be monitored closely and controlled to limit the risk of further dissection or rupture. Vascular changes do not normalize after pregnancy, thus increasing the risk for subsequent pregnancies. Therefore, aortic dissection may be considered a contraindication to further pregnancy, thus necessitating effective contraception. ${ }^{10}$

We chose a regional technique for this patient's Cesarean section which was performed at 32 weeks gestation because the aneurysm was partially repaired and the situation was reasonably well controlled, 
as opposed to a patient presenting with an acute dissecting aortic aneurysm at that gestational age. The surgery was performed in the cardiac operating room with drugs to manipulate the heart rate and blood pressure readily available. The anesthesia team involved a cardiac anesthesiologist and an obstetric anesthesiologist adept at caring for high-risk obstetric patients. Although epidural anesthesia is more controlled, it is slower in onset and has a risk of inadequate block which could be disastrous in this patient. Hence we chose spinal anesthesia as our predominant anesthetic. The combined spinal-epidural technique would provide us with the capability to extend the duration of the block with the epidural catheter, in the event of an unforeseen delay in the completion of the surgery, and also facilitate postoperative analgesia. This patient also had an elective sterilization following the Cesarean section.

\section{Conclusion}

A pregnant patient with a dissecting aortic aneurysm presents a considerable challenge for anesthesiologists, obstetricians and cardiovascular surgeons. Proper management required consultations among the above departments, including cardiology and perinataology physicians. With appropriate care, a successful outcome for the mother and the baby can be achieved as in our case, where the dissecting aneurysm was partially repaired during the $14^{\text {th }}$ week, with successful continuation of the pregnancy to 32 weeks.

\section{Acknowledgements}

The authors gratefully acknowledge the invaluable help provided by Ms. Sonia Perinovic in the preparation of the manuscripte. We thank Jane C.K. Fitch MD for her expert suggestions and editorial comments.

\section{References}

1 Wilson SK, Hutchins GM. Aortic dissecting aneurysms: causative factors in 204 subjects. Arch Pathol Lab Med 1982; 106: 175-80.

2 Jayaram A, Carp HM, Davis L, Jacobson SL. Pregnancy complicated by aortic dissection: caesarean delivery during extradural anaesthesia. Br J Anaesth 1995; 75 : 358-60.

3 Ecknauer E, Schmidlin D, Jenni R, Schmid ER. Emergency repair of incidentally diagnosed ascending aortic aneurysm immediately after caesarean section. $\mathrm{Br}$ J Anaesth 1999; 83: 343-5.

4 Weissmann-Brenner A, Schoen R, Divon MY. Aortic dissection in pregnancy. Obstet Gynecol 2004; 103(5Pt 2): 1110-3.
5 Gardner TJ. Acute aortic dissection. In: Kaiser LR, Kron IL, Spray TL (Eds). Mastery of Cardiothoracic Surgery. Philadelphia: Lippincott-Raven; 1998; 49: 469.

6 Kouchoukos NT, Blackstone EH, Doty DB, Hanley FL, Karp RB. Cardiac Surgery. Morphology, Diagnostic Criteria, Natural History, Techniques, Results, and Indications, $3^{\text {rd }}$ ed., vol. 2. UT: Churchill Livingstone; 2003: 1836.

7 Ferguson JE, Ueland K, Stinson EB, Maly RP. Marfan's syndrome: acute aortic dissection during labor, resulting in fetal distress and cesarean section, followed by successful surgical repair. Am J Obstet Gynecol 1983; 147: 759-62.

8 Manalo-Estrella P, Barker AE. Histopathologic findings in human aortic media associated with pregnancy. A study of 16 cases. Arch Pathol 1967; 83: 336-41.

9 Nienaber $C A$, von Kodolitsch $\Upsilon$, Nicolas $V$, et al. The diagnosis of thoracic aortic dissection by noninvasive imaging procedures. N Engl J Med 1993; 328: 1-9.

10 Zeebregts CJ, Schepens MA, Hameeteman TM, Morshuis $W J$, de la Riviere $A B$. Acute aortic dissection complication pregnancy. Ann Thorac Surg 1997; 64: 1345-8.

11 Tritapepe L, Voci P, Pinto G, Brauneis S, Menichetti A. Anaesthesia for caesarean section in a Marfan patient with recurrent aortic dissection. Can J Anaesth 1996; 43: 1153-5.

12 Immer FF, Bansi AG, Immer-Bansi AS, et al. Aortic dissection in pregnancy: analysis of risk factors and outcome. Ann Thorac Surg 2003; 76: 309-14. 